\title{
Atypical Epidemiologic Finding in Association between Depression and Alcohol Use or Smoking in Korean Male: Korean Longitudinal Study of Aging
}

\author{
Jin-Won Noh', Hee-Soon Juon², Sanghoon Lee ${ }^{3}$, and Young Dae Kwon ${ }^{4} \bowtie$ \\ ${ }^{1}$ Department of Healthcare Management, Eulji University, Seongnam, Republic of Korea \\ ${ }^{2}$ Department of Health, Behavior and Society, Johns Hopkins Bloomberg School of Public Health, Baltimore, USA \\ ${ }^{3}$ Medical Department, Eli Lilly and Company Ltd, Seoul, Republic of Korea \\ ${ }^{4}$ Department of Humanities and Social Medicine, College of Medicine and Catholic Institute for Healthcare Management, \\ The Catholic University of Korea, Seoul, Republic of Korea
}

Objective The purpose of this study is to examine the relationship between substance use and depressive symptoms in a cohort of Koreans aged 45 years and older from a large, population-based study. Using the 2006 Korean Longitudinal Study of Aging, we estimated the prevalence of depressive symptoms and its association with smoking and alcohol use.

Methods Depressive symptoms were measured using the CES-D 10-item scale. Age, marital status, educational attainment, employment and any disability were the control variables. Because there were gender differences in smoking and alcohol use, we also performed a separate analysis by gender.

Results In the multivariable logistic regression, ex-drinkers were more likely to be depressed than non-drinkers (OR, 1.37; $95 \%$ CI, 1.08-1.74 for males; OR, 1.78; 95\% CI, 1.23-2.57 for females). Compared to non-drinkers, males with moderate drinking habits (OR, 0.75; 95\% CI, 0.63-0.90) were less likely to be depressed, whereas heavy male drinkers were more likely to be depressed (OR, 1.43; 95\% CI, 1.07-1.91). Female smokers were more likely to be depressed than female non-smokers (OR, 2.07; 95\% CI, 1.51-2.83).

Conclusion This study showed atypical pattern of relationship between smoking and depression and U-shaped relationship between depressive symptoms and alcohol consumption in male population. Both of these findings could be inferred from that these regional characteristics might be cross-sectional finding of chronologic transition result from a rapid rise of late life depression in Korea.

Psychiatry Investig 2014;11(3):272-280

Key Words Alcohol, Depressive symptom, Gender, Smoking.

\section{INTRODUCTION}

Depressive disorder is one of the most commonly occurring mental disorders and as such is considered a major health issue. The World Health Organization (WHO) projected that depression will become one of three leading causes of burden of disease by the year 2030. ${ }^{1}$ In a nationwide

Received: June 12, 2013 Revised: August 27, 2013

Accepted: November 4, 2013 Available online: July 21, 2014

$\square$ Correspondence: Young Dae Kwon, MD, PhD

Department of Humanities and Social Medicine, College of Medicine and Catholic Institute for Healthcare Management, The Catholic University of Korea, 222 Banpo-daero, Seocho-gu, Seoul 137-701, Republic of Korea Tel: +82-2-2258-8251, Fax: +82-2-2258-8257, E-mail: snukyd1@naver.com

(a) This is an Open Access article distributed under the terms of the Creative Commons Attribution Non-Commercial License (http://creativecommons.org/licenses/by$\mathrm{nc} / 3.0$ ) which permits unrestricted non-commercial use, distribution, and reproduction in any medium, provided the original work is properly cited. survey by the Centers for Disease Control and Prevention (CDC), $9 \%$ of U.S. adults have at least some symptoms of depression. Depression is widely prevalent across countries and among all ethnic and racial groups. ${ }^{2-4}$

When left untreated, depression is as costly as heart disease or AIDS to the U.S. economy, amounting to over $\$ 51$ billion in absenteeism from work and lost productivity as well as $\$ 26$ billion in direct treatment costs. ${ }^{5}$ The annual cost per case for depression ranges from $\$ 1000$ to $\$ 2500$ for direct costs and $\$ 2000$ to $\$ 3700$ for morbidity costs. ${ }^{6}$

In Korea, the depression rate has increased continuously. The prevalence of depressive symptoms in Korea in 1998 measured by CES-D 10 is $23.1 \%$ in males and $27.4 \%$ in females (the cut off is above 16), and these rates were somewhat higher than those found in the U.S. and Western countries. ${ }^{7}$ Depression has become a major social issue due to the 
increasing suicidal rate, particularly since the 1997 economic crisis in Korea. ${ }^{8}$ In 2009, Korea ranked the highest in suicidal rate among OECD countries; ${ }^{9}$ hence, the government forecasted the legalization of mental health screening.

The exact causes of depression for a particular individual are not fully known; however, certain factors increase a person's risk for depression. These factors include being female, a history of previous depression and a family history of depression, stressors and ages. ${ }^{10-16}$ Moreover, the strongest risk factor for late-life depression is physical illness resulting in disability. ${ }^{17-19}$

Substance abuse along with alcohol dependence frequently coexists with depressive disorders as well..$^{20,21}$ People with a history of alcohol dependence are four times more likely to have depression compare to the general population. ${ }^{22,23}$ In addition, marijuana users are four times more likely to develop depression. ${ }^{24}$ Cigarette smoking and depression are also significantly associated. ${ }^{25,26}$ People who are prone to depression face a $25 \%$ chance of becoming depressed when they quit smoking, and this increased risk persists for at least 6 months. ${ }^{27}$ Moreover, depressed smokers are unlikely to stop smoking. Only about 6\% remain smoke-free after a year. ${ }^{28}$

The bidirectional relationship between substance abuse and depression is also different by genders. Women have stronger relationship between depression and substance abuse. The genetic susceptibility of dopamine system, for example the dopamine D4 receptor (DRD4) polymorphism which has a major role in addiction and substance abuse, ${ }^{29}$ shows that gender could contribute to heterotypical manifestation of comorbidity of substance abuse and depression. ${ }^{30}$ Few studies examined the relationship between substance use and depressive symptoms in a community population in Korea. In addition, little attention has paid to gender differences in these relationships among adults aged 45 and over who are in the high risk group of having depressive symptoms after early retirement. Thus, the present study focused on gender differences in the relationship between substance use and depressive symptoms and its relationship with gender.

\section{METHODS}

We used data from the 2006 Korean Longitudinal Study of Aging (KLoSA), which was performed by the Korean Labor Institute and funded by the Korean Ministry of Labor. The population of KLoSA participants includes adults aged 45 or more. Although other surveys of the elderly in other countries have used adults aged 50 and over, KLoSA extended its population group to include those aged 45-49. Those have been thorough career changes during the middle ages. It has become an important social issue ever since the financial cri- sis in the late 1990s, with many people in the 45-49 year age group having been laid off from their jobs. The sampling frame of KLoSA comprises enumeration districts (EDs), as identified by the National Statistical Office's 2005 Census. Under this frame, Apartment EDs and Ordinary housing (non-apartment) EDs totaled 261,237, excluding the island areas and institutions (social welfare facilities). 1,000 sample districts were first allocated into 15 districts by municipal city and province, and the rest were allocated in proportion to the number of population. A total of 803 districts and 197 districts were each allocated in the urban area and rural area, respectively. We used the 1st KLoSA panel data of 2006 with 10,254 respondents. The household response rate was $70.7 \%$.

The short-form Center for Epidemiological Studies-Depression 10-item scale (CES-D 10) was used as the outcome variable. CES-D 10 was developed for Epidemiological Studies of the Elderly (EPESE), and is used as a screening measurement for depression of older adults. ${ }^{31}$ The respondents were asked whether they had such feelings and actions in the past week (i.e., depressed, feelings of guilt, worthlessness and helplessness, psychomotor retardation, loss of appetite, sleep difficulties). Responses were provided on a four-point Likerttype scale from never $(=0)$ to always $(=3)$. The ten items were summed in order to construct a scale of depressive symptoms $(n=10, \alpha=0.87)$ and used a cut-off point of 10 which was proved for its strong correlation and retest stability compared to cut-off point of 16 for CES-D 20-item version. ${ }^{32}$

Cigarette smoking and alcohol use were used as independent variables. Alcohol use was divided into four categories: non-drinker, past drinker, current moderate drinker and current heavy drinker. Non-drinker means people have never tried alcohols, past drinker means people used to drink alcohol before but quit the alcohol and current drinker means people drink alcohol currently. There are five yes or no questions to measure the drinking behavior; "Experience that feel that will should quit drinking", "Experience blamed about drinking habit", "Experience that get angry because of criticism about drinking", "Guilt experience about drinking", and "Experience drinking in the morning." Drinking behavior was categorized as current moderate drinker when total score was 0 and current heavy drinker when the total score was 1 or more. Cigarette smokers were categorized into three: non-smoker, past smoker and current smoker. Non-smoker means people have never smoked, past smoker means people smoked before but quit the smoking, and current smoker means people smoke continuously. Age, education level, marital status, employment, self-rated health status, disable status and region were used as control variables. Participant education level was categorized as follows: 1) elementary school or under, 2) middle school completed, 3) high school completed, 
and 4) college or more. Marital status was categorized as either unmarried (separated/divorced/widowed/never married/missing) (0) or married (currently married/living with a partner) (1). Employment status and disabled status diagnosed by a physician were categorized as no (0) or yes (1). The respondents also categorized self-rated health status as follows: 1) very good, 2) good, 3) fair, 4) poor and 5) very poor. Region was divided by 1) urban, 2) rural.

Four sets of analyses were conducted. First, descriptive analyses were performed to describe the background information on the sample. Because there were gender differences in depressive symptoms and alcohol use and cigarette smoking, a separate analysis were performed according to gender. Second, univariable logistic analysis was performed to examine the relationship between depressive symptoms and independent and control variables. For continuous variables, such as age, linearity was checked using the logit transformed smooth analysis. Finally, multivariable logistic regression was conducted to examine the relationship between substance use and depressive symptoms after adjusting all the control variables. For the analysis, the final sample of 10,181 was used (99\% of the total sample) after excluding the missing cases $(n=73)$. All analyses were performed with STATA version 11.2 .

This study was approved by the Institutional Review Board of the Catholic University of Korea with a waiver for informed consent. There are no identified risks to the subjects of this study because the survey data were analyzed anonymously.

\section{RESULTS}

Demographic characteristics of participants are shown in Table 1. The sample consisted of 10,181 Koreans living in Korea. The mean age was 61.7 years (SD 11.1), ranging from 45 to 105 years. About 44\% were male. Approximately onehalf $(47.0 \%)$ had elementary school or under education and approximately four-fifths were married, and two-thirds were unemployed. About 31\% reported their health status as very poor $(6.7 \%)$ to poor, and $6.5 \%$ reported having a disabled status by their doctor's decision. Moreover, approximately $77 \%$ lived in the urban area.

Figure 1 conveys gender differences in substance use and depressive symptoms. The prevalence of depressive symp-

Table 1. Characteristics of the study population $(N=10,181)$

\begin{tabular}{|c|c|c|c|c|c|c|c|}
\hline & \multirow{2}{*}{ Variable } & \multicolumn{2}{|c|}{ Total } & \multicolumn{2}{|c|}{ Male } & \multicolumn{2}{|c|}{ Female } \\
\hline & & $\mathrm{N}$ & $\%$ & $\mathrm{~N}$ & $\%$ & $\mathrm{~N}$ & $\%$ \\
\hline Gender & & 10,181 & 100.0 & 4,440 & 43.6 & 5,741 & 56.4 \\
\hline Age & Mean (SD), (min, $\max )$ & $61.7(11.1)$ & $(45,105)$ & $61.2(10.6)$ & $(45,96)$ & $62(11.5)$ & $(45,105)$ \\
\hline \multirow[t]{4}{*}{ Education } & Elementary school or under & 4,776 & 47.0 & 1,412 & 31.8 & 3,364 & 58.7 \\
\hline & Middle school completed & 1,645 & 16.2 & 754 & 17.0 & 891 & 15.5 \\
\hline & High school completed & 2,698 & 26.5 & 1,493 & 33.7 & 1,205 & 21.0 \\
\hline & College or more & 1,054 & 10.4 & 778 & 17.5 & 276 & 4.8 \\
\hline \multirow[t]{2}{*}{ Marital status } & $\begin{array}{l}\text { Unmarried (separated/ } \\
\text { divorced/widowed/ } \\
\text { never married/missing) }\end{array}$ & 2,249 & 22.1 & 366 & 8.3 & 1,883 & 32.8 \\
\hline & $\begin{array}{l}\text { Married (currently married/ } \\
\text { living with a partner) }\end{array}$ & 7,930 & 77.9 & 4,073 & 91.7 & 3,857 & 67.2 \\
\hline \multirow[t]{2}{*}{ Employment } & Yes & 3,870 & 38.0 & 2,489 & 56.1 & 1,381 & 24.1 \\
\hline & No & 6,311 & 62.0 & 1,951 & 43.9 & 4,360 & 75.9 \\
\hline \multirow{5}{*}{$\begin{array}{l}\text { Self-rated health } \\
\text { status }\end{array}$} & Very good & 356 & 3.5 & 214 & 4.8 & 142 & 2.5 \\
\hline & Good & 3,494 & 34.3 & 1,840 & 41.4 & 1,654 & 28.8 \\
\hline & Fair & 3,189 & 31.3 & 1,357 & 30.6 & 1,832 & 31.9 \\
\hline & Poor & 2,458 & 24.1 & 783 & 17.6 & 1,675 & 29.2 \\
\hline & Very poor & 684 & 6.7 & 246 & 5.5 & 438 & 7.6 \\
\hline \multirow{2}{*}{$\begin{array}{l}\text { Disable status by } \\
\text { doctor's decision }\end{array}$} & Yes & 657 & 6.5 & 397 & 8.9 & 260 & 4.5 \\
\hline & No & 9,524 & 93.6 & 4,043 & 91.1 & 5,481 & 95.5 \\
\hline \multirow[t]{2}{*}{ Region } & Urban & 7,874 & 77.3 & 3,430 & 77.3 & 4,444 & 77.4 \\
\hline & Rural & 2,307 & 22.7 & 1,010 & 22.8 & 1,297 & 22.6 \\
\hline
\end{tabular}


toms was 32\% (37.1\% for females; $25.4 \%$ for males). Females had higher rates of depressive symptoms than males $\left(\chi^{2}=\right.$ $156.96, \mathrm{p}<0.001)$. There were gender differences in alcohol use $\left(\chi^{2}=3067.17, \mathrm{p}<0.001\right)$ : more males were current drinkers than females (55.8\% vs. $18.0 \%$ for moderate drinkers; $7.4 \%$ vs. $0.6 \%$ for heavy drinkers). Approximately $30 \%$ had smoked (9.6\% for ex-smokers; $19.3 \%$ for current smokers). There were also gender differences in cigarette smoking $\left(\chi^{2}=3989.26\right.$, $\mathrm{p}<0.001$ ): more males had smoked than females ( $40 \%$ vs. $3 \%$ for current smokers; $21 \%$ vs. $1 \%$ for ex-smokers).

We examined the relationship between age and depressive status by gender (Figure 2). There was a linear relationship between age and depressive symptoms among males: Those males had increased depressive symptoms as they grew older. On the other hand, the relationship between age and depres- sive symptoms was not linear among females. Females had increased depressive symptoms by age 79 , and they had decreased symptoms after age 80 . Thus, we used the spline term for females (e.g., females under 80 years old and females 80 years old or more.)

Univariable and multivariable logistic regression analyses were conducted in order to examine the relationship between substance use and depressive status. It is adjusted for age, education level, marital status, employment status, selfrated health status, disable status, and region to find out the relationship between substance use and depressive status. For both males and females in the logistic regression analyses, age, marital status, educational attainment, employment, health status, disable status and residence were significantly related to having a depressive status (Table 2 and 3 ).

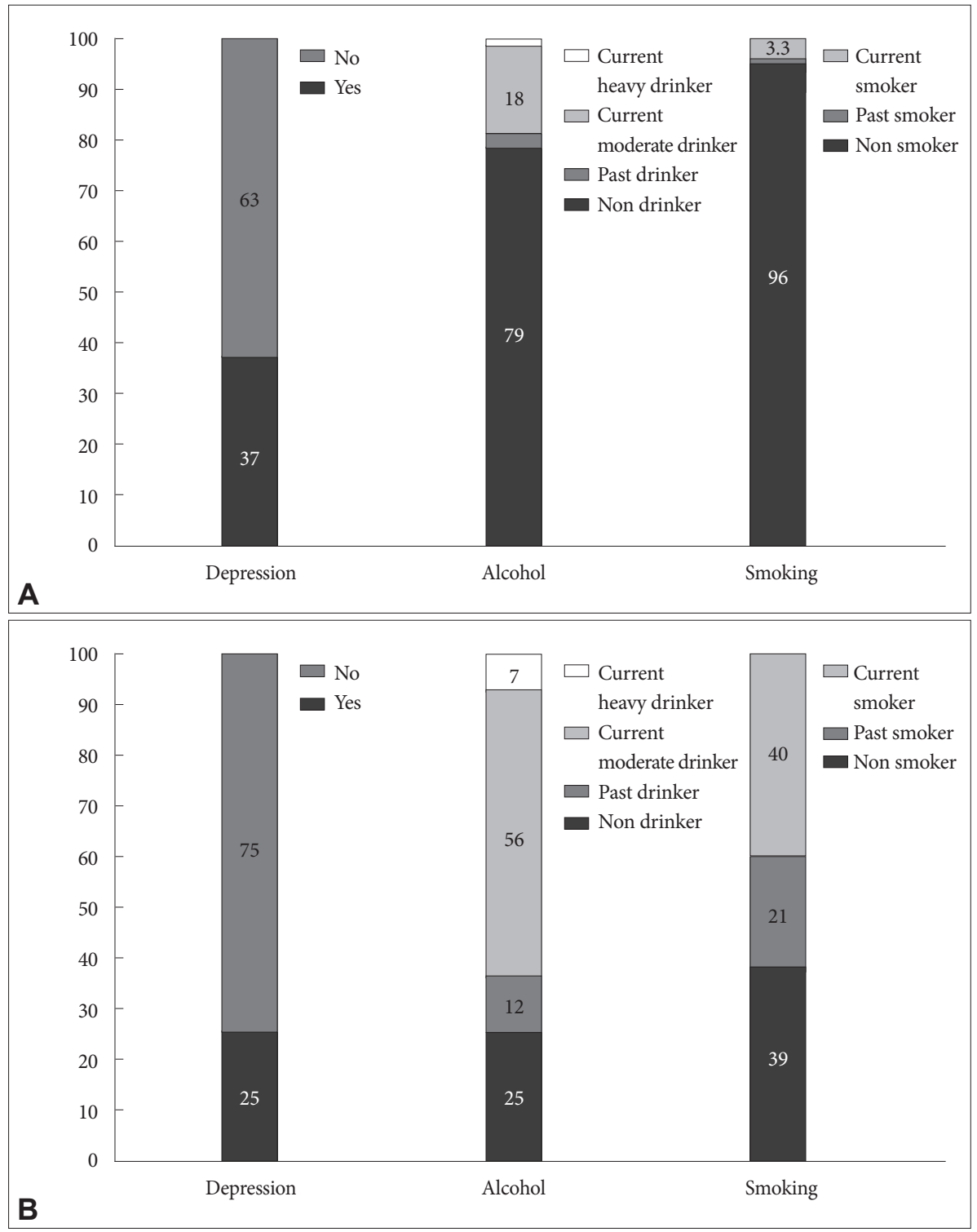

Figure 1. Prevalence of cigarette smoking, alcohol use and depressive status by gender $(N=10,181)$. A: Female. B: Male. 


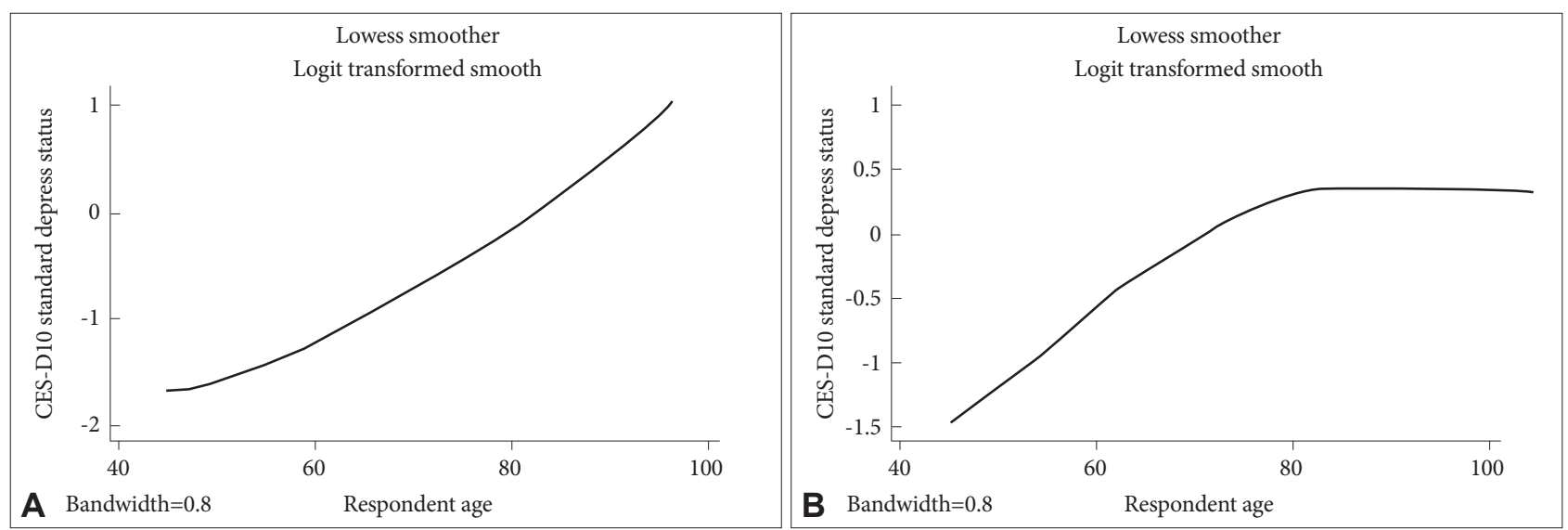

Figure 2. Age and depressive symptom by gender $(N=10,181)$. A: Males. B: Females.

For males, our main variables, alcohol use and cigarette smoking, were significantly associated with the depressive status in the univaribale analysis. Ex-drinkers and current heavy drinkers were more likely to have a depressive status than non-drinkers, while those current moderate drinkers were less likely to have a depressive status than non-drinkers. Ex-smokers were more likely to be depressed than nonsmokers. In the multivariale logistic regression, compared to non-drinkers, those males with moderate drinking (OR, 0.85; 95\% CI, 0.70-1.03; $\mathrm{p}=0.06$ ) showed a tendency of less depressed, whereas heavy male drinkers were more likely to be depressed (OR, 1.45; 95\% CI, 1.07-1.97; $\mathrm{p}<0.05)$. However, the association of cigarette smoking and depression disappeared after adjusting for all the variables).

Table 3 portrays the findings of females. Alcohol use and cigarette smoking were significantly associated with depressive status in the univaribale logistic analysis. Female exdrinkers were more likely to have a depressive status than non-drinkers (OR, 2.29; 95\% CI, 1.63-3.22; $\mathrm{p}<0.01$ ). Exsmokers and current smokers were more likely to be depressed than non-smokers (OR, 3.40; 95\% CI, 1.69-6.84; $\mathrm{p}<0.01$ and OR, 2.70; 95\% CI, 2.01-3.63; $\mathrm{p}<0.01$ ). In the multivariable logistic regression, only cigarette smoking was related to the depressive status: current female smokers were more likely depressed than those non-smokers (OR, 1.71; 95\% CI, 1.222.40; $\mathrm{p}<0.01$ ).

\section{DISCUSSION}

In this study, the prevalence of depressive symptoms was $32 \%$, and this could be primarily engendered by the sensitive cut-off point used in this study (10 or more). Moreover, it is possible that Koreass high suicidal rate among OECD countries for individuals above 45 -years-old might be due to high rates of depressive symptoms. ${ }^{33}$ Education, marital status and region exhibit relationships with depressive symptoms. The more educated and the less socially isolated corresponded to fewer depressive symptoms. This result is concordant with the previous findings. ${ }^{34,35}$ We also found that the prevalence of depressive symptoms is associated with gender (female $>$ male), alcohol use (ex-drinkers, current heavy drinkers $>$ nondrinkers; heavy male drinkers $>$ moderate male drinkers) and cigarette smoking (current female smokers $>$ nonsmokers).

Our findings show that females have higher rates of depressive symptoms than males, which is consistent with previous studies' findings in which being female is associated with depression. ${ }^{711,36,37}$ The higher rates of depression among women may be related to a higher risk of onset, differing gender roles in society and life stresses, such as trauma. ${ }^{36,38}$

Interestingly, there is a linear relationship between age and depressive symptoms for males, while the relationship between age and depressive symptoms is not linear amongst females of the present study. This may result from different life expectancies between males and females. On average, males die about 10 years younger than females; thus, elderly males may likely have more diseases and their health status may be poor compared to females. However, prior studies reported inconsistent findings. A study for Vietnamese refugees reported that old age is associated with more depression. ${ }^{39}$ In contrast, Suen and Morris reported that age was not significantly associated with depression..$^{14}$ In their study, marital status and employment were associated with depressive symptoms more in males than females. This may imply that males are more vulnerable than females to social isolation and loss of social position. However, marital status and employment status were associated with depressive symptoms both males and females in our study. In females, a disabled status is more highly associated with depression than it is in males.

Our findings indicate that alcohol use was significantly associated with depressive symptoms, particular ex-drinkers and current heavy drinkers compared with non-drinkers, and heavy male drinkers compared with moderate male drink- 
Table 2. Logistic regression analyses of depressive symptoms among Korean males $(N=4,440)$

\begin{tabular}{|c|c|c|}
\hline Variable & Unadjusted OR (95\% CI) & Adjusted OR (95\% CI) \\
\hline Age & $1.05(1.04,1.05)^{\ddagger}$ & $1.01(1.00,1.02)$ \\
\hline \multicolumn{3}{|l|}{ Education } \\
\hline Elementary school or under & 1.00 & 1.00 \\
\hline Middle school completed & $0.58(0.48,0.71)^{\ddagger}$ & $0.85(0.68,1.06)$ \\
\hline High school completed & $0.38(0.32,0.45)^{\ddagger}$ & $0.77(0.63,0.94)^{\ddagger}$ \\
\hline College or more & $0.27(0.22,0.34)^{\ddagger}$ & $0.59(0.45,0.76)^{\ddagger}$ \\
\hline \multicolumn{3}{|l|}{ Marital Status } \\
\hline Unmarried (separated/divorced/widowed/never married/missing) & 1.00 & 1.00 \\
\hline Married (currently married/living with a partner) & $0.28(0.22,0.34)^{\ddagger}$ & $0.35(0.28,0.45)^{\ddagger}$ \\
\hline \multicolumn{3}{|l|}{ Employment } \\
\hline Yes & 1.00 & 1.00 \\
\hline No & $1.31(1.27,1.36)^{\ddagger}$ & $1.10(1.05,1.16)^{\ddagger}$ \\
\hline Self-rated health status $(1-5)$ & $2.54(2.35,2.74)^{\ddagger}$ & $2.08(1.90,2.28)^{\ddagger}$ \\
\hline \multicolumn{3}{|l|}{ Disable status } \\
\hline No & 1.00 & 1.00 \\
\hline Yes & $2.59(2.09,3.19)^{\ddagger}$ & $1.05(0.82,1.34)$ \\
\hline \multicolumn{3}{|l|}{ Region } \\
\hline Urban & 1.00 & 1.00 \\
\hline Rural & $1.71(1.47,1.99)^{\ddagger}$ & $1.39(1.17,1.66)^{\ddagger}$ \\
\hline \multicolumn{3}{|l|}{ Alcohol use } \\
\hline Non-drinker & 1.00 & 1.00 \\
\hline Past drinker & $1.70(1.37,2.12)^{\ddagger}$ & $1.06(0.83,1.37)$ \\
\hline Current moderate drinker & $0.66(0.56,0.77)^{\ddagger}$ & $0.85(0.70,1.03)^{*}$ \\
\hline Current heavy drinker & $1.26(0.96,1.64)^{*}$ & $1.45(1.07,1.97)^{\dagger}$ \\
\hline \multicolumn{3}{|l|}{ Cigarette smoking } \\
\hline Non-smoker & 1.00 & 1.00 \\
\hline Past smoker & $1.30(1.08,1.55)^{\ddagger}$ & $1.06(0.87,1.31)$ \\
\hline Current smoker & $1.04(0.89,1.21)$ & $1.13(0.94,1.36)$ \\
\hline
\end{tabular}

${ }^{*} \mathrm{p}<0.10,{ }^{\dagger} \mathrm{p}<0.05,{ }^{\ddagger} \mathrm{p}<0.01$. OR: odds ratio, CI: confidence interval

ers. This finding is consistent with previous evidence indicating that ex-drinkers had slightly higher depressive symptoms. ${ }^{40}$ Likewise, Greenfield et al. reported that female exdrinkers with prior occasions of heavy drinking showed higher levels of depression. ${ }^{41}$ In the present study, the female group does not exhibit a statistically significant relationship between alcohol use and depression. There is a possibility of an underestimation for heavy drinker among females, and of a difference in female social status compared with males, for example, homeless and hospitalized due to being mentally ill. Thus, some females may be excluded from the methods of general data collection, such as responding to daytime phone calls.

Interestingly, the relationship between depressive symptoms and alcohol consumption in male was U-shaped, indicating that moderate male drinkers were less likely to be de- pressed as compared with non-drinkers and heavy drinkers. Further, this finding is coincident with another Korean epidemiologic study. ${ }^{42}$ Commonly, alcohol-use and depression shows a linear correlation. However, some studies suggested that moderate alcohol use is associated with lower depressive symptoms compared with non-alcohol use and heavy alcohol use 43,44 because moderate alcohol use could relieve stress and anxiety and thus improve one's mood. ${ }^{45}$

The relationship between cigarette smoking and depressive symptoms in males could not be found. This finding is unconformable with the previous consistent findings, which indicated that smoking is significantly associated with depression. ${ }^{46}$ Those atypical epidemiologic findings could be caused by a rapid rise and pattern-change prevalence of late-life depression in Korea. The various patterns of the prevalence rate 
Table 3. Logistic regression analyses of depressive symptoms among Korean females $(N=5,741)$

\begin{tabular}{|c|c|c|}
\hline Variable & Unadjusted OR (95\% CI) & Adjusted OR $(95 \% \mathrm{CI})$ \\
\hline Age (continuous) & $1.05(1.04,1.05)^{\dagger}$ & $\mathrm{N} / \mathrm{A}$ \\
\hline Age (45-79) & $1.06(1.05,1.06)^{\dagger}$ & $1.00(1.00,1.01)$ \\
\hline Age $(\geq 80)$ & $0.97(0.93,0.99)^{*}$ & $0.98(0.94,1.02)$ \\
\hline \multicolumn{3}{|l|}{ Education } \\
\hline Elementary school or under & 1.00 & 1.00 \\
\hline Middle school completed & $0.48(0.41,0.56)^{\dagger}$ & $0.95(0.78,1.14)$ \\
\hline High school completed & $0.27(0.23,0.32)^{\dagger}$ & $0.68(0.56,0.83)^{\dagger}$ \\
\hline College or more & $0.17(0.12,0.25)^{\dagger}$ & $0.53(0.36,0.78)^{\dagger}$ \\
\hline \multicolumn{3}{|l|}{ Marital Status } \\
\hline Unmarried (separated/divorced/widowed/never married/missing) & 1.00 & 1.00 \\
\hline Married (currently married/living with a partner) & $0.34(0.35,0.44)^{\dagger}$ & $0.60(0.52,0.69)^{\dagger}$ \\
\hline \multicolumn{3}{|l|}{ Employment } \\
\hline No & 1.00 & 1.00 \\
\hline Yes & $1.16(1.12,2.00)^{\dagger}$ & $1.04(1.00,1.08)^{\dagger}$ \\
\hline Self-rated health status $(1-5)$ & $2.85(2.66,3.06)^{\dagger}$ & $2.44(2.26,2.63)^{\dagger}$ \\
\hline \multicolumn{3}{|l|}{ Disable status } \\
\hline No & 1.00 & 1.00 \\
\hline Yes & $3.06(2.36,3.96)^{\dagger}$ & $1.46(1.10,1.94)^{\dagger}$ \\
\hline \multicolumn{3}{|l|}{ Region } \\
\hline Urban & 1.00 & 1.00 \\
\hline Rural & $1.47(1.30,1.67)^{\dagger}$ & $1.19(1.03,1.38)^{\dagger}$ \\
\hline \multicolumn{3}{|l|}{ Alcohol use } \\
\hline Non-drinker & 1.00 & 1.00 \\
\hline Past drinker & $2.29(1.63,3.22)^{\dagger}$ & $1.15(0.78,1.70)$ \\
\hline Current moderate drinker & $0.91(0.79,1.05)$ & $1.15(0.97,1.36)$ \\
\hline Current heavy drinker & $1.71(0.87,3.36)$ & $1.68(0.79,3.58)$ \\
\hline \multicolumn{3}{|l|}{ Cigarette smoking } \\
\hline Non-smoker & 1.00 & 1.00 \\
\hline Past smoker & $3.40(1.69,6.84)^{\dagger}$ & $1.50(0.68,3.33)$ \\
\hline Current smoker & $2.70(2.01,3.63)^{\dagger}$ & $1.71(1.22,2.40)^{\dagger}$ \\
\hline
\end{tabular}

${ }^{*} \mathrm{p}<0.05,{ }^{\dagger} \mathrm{p}<0.01$. OR: odds ratio, CI: confidence interval, N/A: not available

occurring at different ages in counties suggest that there is strong influence social factors on late-life depression. Hence, we could conjecture that other social factors which raise latelife depression in Korean males dilute the association of smoking and depression. In the case of females, despite the up-rising of other social factors, the rapid-rising rate of smoking prevalence of females might continue to show an association with depression compared to males who already showed a 'ceiling effect' of high prevalence rate of smoking.' Therefore, in the rapid-transition to an elderly society in Korea, epidemiology and intensities of various contribute factors of depression seem to be changing rapidly.

In the view of public mental health, the current elderly so- ciety of Korea has many cultural influences. Members of the Korean elderly society lived through dramatic sociocultural changes: the Korean War (1950-1953), the post-war industrialization, westernization of the Korean society, and social values shifting from frugality to wealth. People moved from rural areas to the cities and big families have been broken into nuclear families; thus, emotional support from family has been weakened. These abrupt and dramatic changes in the social and economic environments of Korea have likely contributed to depression in the Korean society. ${ }^{47}$ Thus, there are several cultural influences on the psychological burden of social success for males, and obedience and abstinence for females in Korea. ${ }^{7}$ Hence, males are more prone to be depres- 
sive along with loss of their social position and isolation, and consequently, they are more likely to be heavy drinkers. ${ }^{48}$

The pathology of alcohol and smoking dependence is related to genetic factors. ${ }^{49}$ Hence, heavy drinking and smoking groups may be more heterogeneous than other groups analyzed. Therefore, different or more aggressive approaches may be needed in order to unravel the variables associated with depression among such heterogeneous groups.

We note that this study presented differences in the relationships between depression and substance use by gender, in counter contrast to another study that showed no differences by gender. ${ }^{40}$ Demographic characteristics as well significantly different by gender. These issues can influence the results and it could be as one of limitations. Further studies will be needed to clarify this issue. The present study is a crosssectional analysis, and future studies will be required to identify trends in depression and its risk factors. Moreover, data collection methods should be re-evaluated as there may be an inherent selection bias of phone surveys, including time of phone calls as well as the ability to contact homeless individuals and those hospitalized due to mental illness.

Based on our findings, we propose that distinct male and female intervention strategies should be considered for the treatment of depression in elderly Koreans. For males, social support to combat social isolation and therapeutic intervention for heavy alcohol drinkers, and for females, support for the physically disabled and treatment for smoking, may help reduce the prevalence and severity of depression and its related social burden.

\section{REFERENCES}

1. Mathers CD, Loncar D. Projections of global mortality and burden of disease from 2002 to 2030. PLoS Med 2006;3:e442.

2. Kessler RC, McGonagle KA, Swartz M, Blazer DG, Nelson CB. Sex and depression in the National Comorbidity Survey. I: Lifetime prevalence, chronicity and recurrence. J Affect Disord 1993;29:85-96.

3. Weissman MM, Bland RC, Canino GJ, Karavelli C, Greenwald S, Hwu HG, et al. Cross-national epidemiology of major depression and bipolar disorder. JAMA 1996;276:293-299.

4. Miranda J, Lawson W, Escobar J; NIMH Affective Disorders Workgroup. Ethnic minorities. Ment Health Serv Res 2002;4:231-237.

5. Greenberg PE, Stiglin LE, Finkelstein SN, Berndt ER. The economic burden of depression in 1990. J Clin Psychiatry 1993;54:405-418.

6. Luppa M, Heinrich S, Angermeyer M, Konig HH, Riedel-Heller SG. Cost-of-illness studies of depression: a systematic review. J Affect Disord 2007;98:29-43.

7. Cho MJ, Nam JJ, Suh GH. Prevalence of symptoms of depression in a nationwide sample of Korean adults. Psychiatry Res 1998;81:341-352.

8. Kwon JW, Chun HR, Cho SI. A close look at the increase in suicide rates in South Korea from 1986-2005. BMC Public Health 2009;9:72.

9. Organization for Economic Co-operation and Development. OECD Health Data 2011. Available at: http://stats.oecd.org/index.aspx?Data SetCode=HEALTH_STAT. Accessed January 17, 2013.

10. Birmaher B, Williamson DE, Dahl RE, Axelson DA, Kaufman J, Dorn $\mathrm{LD}$, et al. Clinical presentation and course of depression in youth: does onset in childhood differ from onset in adolescence? J Am Acad Child Adolesc Psychiatry 2004;43:63-70.

11. Ried LD, Planas LG. Aging, health, and depressive symptoms: are women and men different? J Womens Health (Larchmt) 2002;11:813824.

12. Burcusa SL, Iacono WG. Risk for recurrence in depression. Clin Psychol Rev 2007;27:959-985.

13. Barbadoro P, Cotichelli G, Chiatti C, Simonetti ML, Marigliano A, Di Stanislao F, et al. Socio-economic determinants and self-reported depressive symptoms during postpartum period. Women Health 2012;52: 352-368.

14. Lopez AD, Mathers CD, Ezzati M, Jamison DT, Murray CJ. Global and regional burden of disease and risk factors, 2001: systematic analysis of population health data. Lancet 2006;367:1747-1757.

15. Murakumi J. Gender and depression: explaining the different rates of depression between men and women. Perspect Psychol 2002;5:27-34.

16. Suen LJ, Morris DL. Depression and gender differences: focus on Taiwanese American older adults. J Gerontol Nurs 2006;32:28-36.

17. Yang Y, George LK. Functional disability, disability transitions, and depressive symptoms in late life. J Aging Health 2006;17:263-292.

18. Schieman S, Plickert G. Functional limitations and changes in levels of depression among older adults: a multiple-hierarchy stratification perspective. J Gerontol B Psychol Sci Soc Sci 2006;62:S36-S42.

19. Brenes GA, Penninx BW, Judd PH, Rockwell E, Sewell DD, Wetherell JL. Anxiety, depression and disability across the lifespan. Aging Ment Health 2008;12:158-163.

20. Grant BF, Hasin DS, Chou SP, Stinson FS, Dawson DA. Nicotine dependence and psychiatric disorders in the United States: results from the national epidemiologic survey on alcohol and related conditions. Arch Gen Psychiatry 2004;61:1107-1115.

21. Sullivan LE, Fiellin DA, O'Connor PG. The prevalence and impact of alcohol problems in major depression: a systematic review. Am J Med 2005;118:330-341.

22. Hasin D, Liu X, Nunes E, McCloud S, Samet S, Endicott J. Effects of major depression on remission and relapse of substance dependence. Arch Gen Psychiatry 2002;59:375-380.

23. Hasin DS, Grant BF. Major depression in 6050 former drinkers: association with past alcohol dependence. Arch Gen Psychiatry 2002;59: 794-800.

24. Bovasso GB. Cannabis abuse as a risk factor for depressive symptoms. Am J Psychiatry 2001;158:2033-2037.

25. Kendler KS, Neale MC, MacLean CJ, Heath AC, Eaves LJ, Kessler RC. Smoking and major depression. A causal analysis. Arch Gen Psychiatry 1993;50:36-43

26. Johnson EO, Rhee SH, Chase GA, Breslau N. Comorbidity of depression with levels of smoking: an exploration of the shared familial risk hypothesis. Nicotine Tob Res 1993;6:1029-1038.

27. Glassman AH, Covey LS, Stetner F, Rivelli S. Smoking cessation and the course of major depression: a follow-up study. Lancet 2001;357: 1929-1932.

28. Pratt LA, Brody DJ. Depression and smoking in the U.S. household population aged 20 and over, 2005-2008. NCHS Data Brief 2010;(34): 1-8.

29. Bobadilla L, Vaske J, Asberg K. Dopamine receptor (D4) polymorphism is related to comorbidity between marijuana abuse and depression. Addict Behav 2013;38:2555-2562.

30. Bookman EB, Taylor RE, Adams-Campbell L, Kittles RA. DRD4 promoter SNPs and gender effects on Extraversion in African Americans. Mol Psychiatry 2002;7:786-789.

31. Kohout FJ, Berkman LF, Evans DA, Cornoni-Huntley J. Two shorter forms of the CES-D (Center for Epidemiological Studies Depression) depression symptoms index. J Aging Health 1993;5:179-193.

32. Andresen EM, Malmgren JA, Carter WB, Patrick DL. Screening for depression in well older adults: evaluation of a short form of the CESD (Center for Epidemiological Studies Depression Scale). Am J Prev 
Med 1994;10:77-84.

33. World Health Organization. The world health report 2012; mental health suicide rates per 100,000 by country, years and sex. Available at: http://www.who.int/mental_health/prevention/suicide_rates/en/index.html. Accessed February 15, 2013.

34. Propper C, Jones K, Bolster A, Burgess S, Johnston R, Sarker R. Local neighbourhood and mental health: evidence from the UK. Soc Sci Med 2005;61:2065-2083

35. Bjelland I, Krokstad S, Mykletun A, Dahl AA, Tell GS, Tambs K. Does a higher educational level protect against anxiety and depression? The HUNT study. Soc Sci Med 2008;66:1334-1345.

36. Kessler RC, Berglund P, Demler O, Jin R, Koretz D, Merikangas KR, et al. The epidemiology of major depressive disorder: results from the National Comorbidity Survey Replication (NCS-R). JAMA 2003;289: 3095-3105.

37. Goldstein RD, Gruenberg AM. Major depressive disorder in the older adult: implications for women. J Women Aging 2007;19:63-77.

38. Accortt EE, Freeman MP, Allen JJ. Women and major depressive disorder: clinical perspectives on causal pathways. J Womens Health (Larchmt) 2008;17:1583-1590.

39. Yee BWK, Nguyen HT, Ha M. Chronic disease, health beliefs and lifestyle practices among Vietnamese adults: influence of gender and age. Women Ther 2003;26:111-125.

40. Graham K, Massak A, Demers A, Rehm J. Does the association between alcohol consumption and depression depend on how they are measured? Alcohol Clin Exp Res 2007;31:78-88.
41. Greenfield TK, Rehm J, Rogers JD. Effects of depression and social integration on the relationship between alcohol consumption and allcause mortality. Addiction 2002;97:29-38.

42. Park JH, Kim KW, Kim MH, Kim MD, Kim BJ, Kim SK, et al. A nationwide survey on the prevalence and risk factors of late life depression in South Korea. J Affect Disord 2012;138:34-40.

43. Paschall MJ, Freisthler B, Lipton RI. Moderate alcohol use and depression in young adulthood: findings from a national longitudinal study. Am J Public Health 2005;95:453-457.

44. O'Donnell K, Wardle J, Dantzer C, Steptoe A. Alcohol consumption and symptoms of depression in young adults from 20 centuries. J Stud Alcohol 2006;67:837-840.

45. Peele S, Brodsky A. Gateway to nowhere: how alcohol came to be scapegoated for drug abuse. Addiction Res 1998;5:419-426.

46. Bonnet F, Irving K, Terra JL, Nony P, Berthezène F, Moulin P. Anxiety and depression are associated with unhealthy lifestyle in patients at risk of cardiovascular disease. Atherosclerosis 2005;178:339-344.

47. Nakane Y, Ohta Y, Radford M, Yan H, Wang X, Lee HY, et al. Comparative study of affective disorders in three Asian countries. II. Differences in prevalence rates and symptom presentation. Acta Psychiatr Scand 1991;84:313-319.

48. Lee CK, Kwak YS, Yamamoto J, Rhee H, Kim YS, Han JH, et al. Psychiatric epidemiology in Korea. part I: Gender and age differences in Seoul. J Nerv Ment Dis 1990;178:242-246.

49. Wang JC, Kapoor M, Goate AM. The genetics of substance dependence. Annu Rev Genomics Hum Genet 2012;22:241-261. 